\title{
UCRL-CONF-206985
}

LAW RENCE LIVERMORE N A T IO N A L LABORATORY

\section{A Detailed Chemical Kinetic Analysis of Low Temperature Non-Sooting Diesel Combustion}

S. M. Aceves, D. L. Flowers

October 1, 2004

SAE 2005 World Congress

Detroit, MI, United States

April 11, 2005 through April 14, 2005 
This document was prepared as an account of work sponsored by an agency of the United States Government. Neither the United States Government nor the University of California nor any of their employees, makes any warranty, express or implied, or assumes any legal liability or responsibility for the accuracy, completeness, or usefulness of any information, apparatus, product, or process disclosed, or represents that its use would not infringe privately owned rights. Reference herein to any specific commercial product, process, or service by trade name, trademark, manufacturer, or otherwise, does not necessarily constitute or imply its endorsement, recommendation, or favoring by the United States Government or the University of California. The views and opinions of authors expressed herein do not necessarily state or reflect those of the United States Government or the University of California, and shall not be used for advertising or product endorsement purposes. 


\title{
A Detailed Chemical Kinetic Analysis of Low Temperature Non-Sooting Diesel Combustion
}

\author{
Salvador M. Aceves, Daniel L. Flowers \\ Lawrence Livermore National Laboratory
}

\begin{abstract}
We have developed a model of the diesel fuel injection process for application to analysis of low temperature non-sooting combustion. The model uses a simplified mixing correlation and detailed chemical kinetics, and analyzes a parcel of fuel as it moves along the fuel jet, from injection into evaporation and ignition. The model predicts chemical composition and soot precursors, and is applied at conditions that result in low temperature non-sooting combustion. Production of soot precursors is the first step toward production of soot, and modeling precursor production is expected to give insight into the overall evolution of soot inside the engine.

The results of the analysis show that the model has been successful in describing many of the observed characteristics of low temperature combustion. The model predicts results that are qualitatively similar to those obtained for soot formation experiments at conditions in which the EGR rate is increased from zero to very high values as the fueling rate is kept constant. The model also describes the two paths to achieve non-sooting combustion. The first is smokeless rich combustion and the second is modulated kinetics (MK). The importance of the temperature after ignition and the equivalence ratio at the time of ignition is demonstrated, as these parameters can be used to collapse onto a single line all the results for soot precursors for multiple fueling rates. A parametric analysis indicates that precursor formation increases considerably as the gas temperature in the combustion chamber and the characteristic mixing time are increased. The model provides a chemical kinetic description of low temperature diesel combustion that improves the understanding of this clean and efficient regime of operation.
\end{abstract}

\section{Nomenclature}

EGR Molar fraction of exhaust gas recirculation

M Mass of a parcel of fuel inside the jet at time $t$ after fuel evaporation (Equation 1)

$\mathrm{M}_{\mathrm{o}} \quad$ Mass of a parcel of fuel (including entrained air) at the time of fuel evaporation

$\mathrm{t} \quad$ Time after fuel evaporation

$\mathrm{x}, \mathrm{y}, \mathrm{z}$ Composition of fuel, $\mathrm{CxHyOz}$

$\alpha \quad$ Stoichiometric coefficient, defined as $\alpha=x+y / 4-z / 2$

$\phi \quad$ Equivalence ratio inside jet

$\phi_{\mathrm{i}} \quad$ Equivalence ratio at the point of ignition 
$\phi_{0} \quad$ Equivalence ratio when $\mathrm{EGR}=0$. It is an indicator of fueling rate

$\phi(\mathrm{H}) \quad$ Equivalence ratio at the lift-off length

$\tau \quad$ Characteristic mixing time

$\Sigma \quad$ Total moles in EGR composition (Equation 4)

\section{Introduction}

Diesel engines have the high efficiency and low maintenance that makes them the ideal choice for transportation and power generation applications. On the other hand, diesel engines have been identified as contributors to environmental pollution due to their high emissions of $\mathrm{NO}_{\mathrm{x}}$ and particulate matter. New combustion regimes are being explored to reduce emissions from diesel engines while maintaining their high efficiency. Two of these regimes have been discovered in recent years: Smokeless Rich Diesel Combustion (SRDC) [1] and Modulated Kinetics (MK) [2]. These two combustion regimes are collectively known as low temperature non-sooting combustion, a title that may also be applied to Homogeneous Charge Compression Ignition (HCCI) engines [3].

SRDC was recently discovered by Toyota [1]. SRDC has thehigh efficiency of regular diesel combustion while producing very low $\mathrm{NO}_{\mathrm{x}}$ and soot emissions. Very importantly, SRDC offers the possibility of generating a fuel-rich exhaust stream from a diesel engine that contains no PM. This exhaust stream is ideal for regeneration of $\mathrm{NO}_{\mathrm{x}}$ traps, which are considered a strong contender for diesel $\mathrm{NO}_{\mathrm{x}}$ aftertreatment. While $\mathrm{NO}_{\mathrm{x}}$ trap regeneration in regular diesel engines typicallyre sults in an energy penalty, SRDC exhaust can regenerate a $\mathrm{NO}_{\mathrm{x}}$ trap with no energy penalty, considerably improving the potential of $\mathrm{NO}_{\mathrm{x}}$ traps [4]. SRDC is obtained by operating the engine at very high levels of cooled EGR (60\% or more), to keep the temperature inside the diesel jet low enough that no particulate matter can form. The need for high EGR limits the range of operation of SRDC to low power conditions. At higher power output, the $\mathrm{NO}_{\mathrm{x}}$ trap needs to be regenerated by injecting fuel into the exhaust, with the associated loss in system efficiency.

MK combustion was discovered by Nissan $[2,5,6]$. MK is achieved by increasing EGR to a relatively high value $(\sim 30 \%)$ while at the same time delaying fuel injection (from $\sim 7^{\circ}$ BTDC for regular diesel combustion to $\sim 3^{\circ}$ ATDC for MK) and increasing the swirl ratio (from $\sim 3$ to $\sim 5$ ). These operating conditions increase the ignition delay, allowing the injection process to be concluded before ignition occurs. At these conditions, significant air-fuel mixing occurs before combustion, resulting in nearly homogeneous combustion that produces low soot and low $\mathrm{NO}_{\mathrm{x}}$. As in the case of SRDC, MK is limited to low power conditions due to the need for a short injection process that can be concluded before ignition occurs.

Multiple publications have recently been written on SRDC and MK in an attempt to explain the details of these operating modes. These publications include both analysis [79] as well as experiments [10-13], and they have contributed to developing an understanding of low temperature non-sooting combustion. Analysis work [7] has 
explained non-sooting combustion by identifying a region in the temperature-equivalence ratio $(\mathrm{T}-\phi)$ diagram in which soot is produced in an engine. This "soot peninsula" extends down to an equivalence ratio of 2 in composition and between $1600 \mathrm{~K}$ and $2600 \mathrm{~K}$ in temperature. The shape of the soot peninsula was determined from a chemical kinetic model of soot formation [14]. Laser imaging experiments [13] and engine performance experiments [10] have verified these results, and have shown that non-sooting combustion can be achieved by either keeping the combustion temperature below $1600 \mathrm{~K}$ (as done in SRDC) or by mixing the air and fuel to an equivalence ratio below 2 before combustion occurs (as done in MK).

In this paper we conduct an analysis of low temperature non-sooting combustion with a detailed chemical kinetic model and a simplified mixing model. The model incorporates much of the physics of reacting diesel jets that has been observed in laser diagnostic experiments $[15,16]$, and it is therefore capable of explaining much of the characteristics of low temperature non-sooting combustion. The following section describes the model in detail.

\section{The Model}

The model follows the evolution of the diesel fuel jet from injection into evaporation and ignition all the way into combustion. The model captures the physics and chemistry of a parcel of fuel as it travels along the jet during the quasi-steady phase of the diesel injection process. The main features of the model are listed next.

1. Fuel evaporation occurs as the fuel jet entrains hot air and mixes. The amount of air required to evaporate the diesel jet is determined from an energy balance [17]. We assume that no chemistry occurs until all the fuel evaporates due to the relatively low temperature of evaporation.

2. After the fuel is evaporated, chemistry becomes active and entrainment with air in the cylinder continues until ignition occurs. Once ignition occurs (defined as the point in which $1 \%$ of the total available chemical heat is released) we assume that no more air entrains into the core of the fuel jet, since the oxygen is consumed in the outer layers of the jet [17]. N-heptane is used as the diesel fuel surrogate for the chemical kinetic calculations.

3. The combustion process is analyzed during the first $0.5 \mathrm{~ms}$ after the end of evaporation $(0.5 \mathrm{~ms}$ is equivalent to 3 crank angle degrees at $1000 \mathrm{rpm})$. The 0.5 $\mathrm{ms}$ period is long enough to include ignition in all cases considered. Available oxygen inside the jet is typically depleted after the $0.5 \mathrm{~ms}$, although there are a few low temperature cases in which oxygen remains after the $0.5 \mathrm{~ms}$.

4. Results reported in this paper for soot precursors and chemical composition refer to the values calculated at $0.5 \mathrm{~ms}$ after fuel evaporation. Precursors generated at 
this time are likely to have enough time to react and form soot as they travel along the jet. Therefore, soot precursors are expected to be a good indication of soot production in the engine. The exception to this may be the few cases in which oxygen remains inside the jet after the $0.5 \mathrm{~ms}$ period. If oxygen remains, the oxygen is likely to react with the precursors before these have time to consolidate into soot [18], reducing the soot formation potential of precursors. However, the few casesthathave remaining oxygen after the $0.5 \mathrm{~ms}$ have very low precursor concentration due to their low temperature of combustion. Therefore, we expect to obtain good soot predictions from the model for the conditions being analyzed.

5. The model does not consider the process of soot formation from precursors or the process of soot combustion that typically occurs in the jet boundary [15,16]. Only results for soot precursors are presented. While this model presents only part of the overall picture of soot evolution, it is capable of explaining many of the features of low temperature combustion, and it offers insight about the characteristics of the process.

The parameters used in the analysis are listed in Table 1. It is assumed that fuel injection occurs into a combustion chamber at $1000 \mathrm{~K}$ and 83 bar, which are considered typical of diesel engines [19]. It is assumed that the ignition process occurs at constant pressure. Diesel fuel is a mixture of multiple compounds, each evaporating at a different temperature. Previous researchers have analyzed diesel fuel evaporation by considering a pseudo specific heat that averages the sensible and the latent heats over the range of evaporation of the fuel [19]. This approach is used here. The pseudo specific heat of diesel fuel is calculated from fuel characteristics listed in [20].

Once the fuel is evaporated, the model uses n-heptaneas a surrogate for diesel fuel, both for the physical properties (specific heat) and for the chemical properties. A detailed chemical kinetic mechanism for $n$-heptane is used, with 544 species [21]. It is recognized that a diesel fuel that typically includes a significant fraction of aromatics in addition to straight chain alkanes may produce more soot than n-heptane [13]. However, alkanes are a major component of diesel fuel and contribute significantly to soot as precursors build into ring compounds that subsequently evolve into soot. Our model is ideally suited for evaluating the effect of fuel component characteristics on soot generation, and this will be addressed in future work.

Five soot precursors are considered in the analysis, although it is observed that ethylene and acetylene typically represent over $90 \%$ of the total mass of precursors, in agreement with a previous analysis [18].

The mixing process between the fuel jet and the surrounding air is analyzed by specifying a characteristic mixing time, $\tau$. The mixing time is defined as the time in which a parcel of the fuel jet entrains a mass of air equal to $M_{0}$, where $M_{o}$ is the mass of the fuel parcel at the moment of evaporation. $\mathbf{M}_{\mathrm{o}}$ therefore includes the mass of fuel injected plus the mass of entrained air necessary to evaporate the fuel. The mass of the fuel parcel at a time $t$ after the end of the evaporation process is therefore given by the following equation. 
The parameter $\tau$ is an important component of this model, as it completely characterizes the mixing processes that occur during jet evolution. For this reason, the paper includes a parametric analysis on how the selection of $\tau$ affects the results.

Low temperature combustion is obtained at low fueling rates and high EGR fractions. In the original smokeless combustion experiments [1], the fueling rate was kept constant as the EGR rate was increased from zero to a high EGR fraction that resulted in a stoichiometric or slightly rich mixture. In this paper we conduct the analysis in a similar fashion, by analyzing sequences of operating conditions that have the same fueling rates. We start by analyzing engine combustion at zero EGR with an equivalence ratio $\phi_{0}$. We then analyze engine operation as the air is replaced by exhaust gases, while keeping the fueling rate constant (see Figure 1). Analyzing these sequences of operating conditions with equal fueling rates, it is apparent that the parameter $\phi_{\mathrm{o}}$ (equivalence ratio at zero EGR) can be used as an indicator of fueling rate, since it can readily be used to calculate amount of fuel injected in the cylinder. Chemical composition of the gases in the cylinder can be expressed in terms of $\phi_{o}$, EGR and the characteristics of the fuel. First, the composition of the EGR is calculated by conducting a mass and species balance over control volume B (Figure 2), assuming complete combustion and a composition that is overall lean or stoichiometric. The resulting composition of the exhaust gases is:

$\mathrm{x} \phi_{\mathrm{o}} \mathrm{CO}_{2}+\mathrm{y} \phi_{\mathrm{o}} \mathrm{H}_{2} \mathrm{O}+\alpha\left(1-\phi_{\mathrm{o}}-\mathrm{EGR}\right) \mathrm{O}_{2}+3.77 \alpha(1-\mathrm{EGR}) \mathrm{N}_{2}$

where the fuel composition is $\mathrm{C}_{\mathrm{x}} \mathrm{H}_{\mathrm{y}} \mathrm{O}_{\mathrm{z}}$, and $\alpha=\mathrm{x}+\mathrm{y} / 4-\mathrm{z} / 2$. For $\mathrm{n}$-heptane, $\mathrm{x}=7, \mathrm{y}=16, \mathrm{z}=0$ and $\alpha=11$. The composition of the gas mixture inside the combustion chamber can then be calculated by conducting a species balance on control volume A (Figure 2), considering that EGR moles of residual gases with the composition given by Equation (2) are mixed with (1-EGR) moles of fresh charge with the normal composition of air. This composition of the gas mixture is then entrained into the fuel jet at a rate specified by Equation (1).

Once the composition of the gas mixture in the combustion chamber is known, we can derive the following relationship between the overall equivalence ratio in the cylinder, $\phi$, and $\phi_{o}$, EGR and the fuel composition:

$$
\phi=\frac{\phi_{o} \Sigma}{4.77 \alpha(E G R)\left(1-E G R-\phi_{o}\right)+(1-E G R) \Sigma}
$$

in this equation, $\Sigma$ is the total number of moles in the composition of the EGR (Equation 2):

$$
\Sigma=\mathrm{x} \phi_{\mathrm{o}}+\mathrm{y} \phi_{\mathrm{o}}+\alpha\left(1-\phi_{\mathrm{o}}-\mathrm{EGR}\right)+3.77 \alpha(1-\mathrm{EGR})
$$


Figure 3 shows $\phi$ as a function of EGR, with lines corresponding to multiple values of $\phi_{0}$, for n-heptane. This figure is obtained from Equations (3) and (4), and can be used for determining the value of $\phi$ for every operating condition, as the algebraic relationship between $\phi, \phi_{\mathrm{o}}$ and EGR is complex.

Results in this paper are identified in terms of $\phi_{\mathrm{o}}$ and EGR, as $\phi_{\mathrm{o}}$ (fueling rate) relates directly to important engine parameters such as load. Equivalence ratio and chemical composition can be determined from Equations (2-4) and Figure 3 as needed. Some of the figures refer to air-fuel ratio, which is defined in terms of the fresh air only, without considering the oxygen introduced in the cylinder with the EGR:

Air-fuel ratio $=15.1316(1-E G R) / \phi_{o}$

where 15.1316 is the stoichiometric air-fuel ratio of n-heptane on a mass basis.

\section{Results}

Figure 4 shows soot precursors generated during fuel combustion in grams per gram of fuel, as a function of the air-fuel ratio, for $\phi_{0}=0.2$. All the points on the line have the same fueling rate $\left(\phi_{0}=\right.$ constant $)$, and the air-fuel ratio in the figure is changed by increasing the fraction of EGR, according to Equation (5). The level of EGR is indicated by the dots in the figure, each representing 5\% change in EGR fraction. The figure also has three points marked on it (Points 1,2 and 3). Combustion for these three points is described in detail later in the paper. Figure 4 has a very similar shape to the experimental soot production plot obtained experimentally for low temperature combustion [1]. However, it must be remembered that these results cannot be compared directly, as Figure 4 shows precursors, which are only the first step in the evolution of soot, and [1] shows particle matter emissions from the engine.

Figures 5-7 show the combustion details for operating Points 1, 2 and 3 (see Figure 4). These figures show temperature (upper graph), chemical heat release, expressed as a fraction of the total available chemical energy in the fuel (middle graph) and species mass composition inside the jet (lower graph). Mass composition is expressed in arbitrary units, considering that the total mass in the fuel parcel is equal to 1 at the moment of fuel evaporation. From that point, mass is entrained into the parcel at a rate given by Equation 1. Entrainment continues until the point of ignition. After ignition, the overall mass in the fuel parcel does not change. However, composition does change due to chemical reaction. The total mass in the parcel is not shown in Figures 5-7, as the nitrogen region extends beyond the upper limit of the figure.

Figure 5 shows the results for Point 1 , with $25 \%$ EGR and $\phi_{0}=0.2$. At these conditions, ignition occurs approximately $0.2 \mathrm{~ms}$ after evaporation, and the oxygen inside the jet is depleted in approximately $0.1 \mathrm{~ms}$ after ignition. Combustion temperature is slightly over $2000 \mathrm{~K}$, kept relatively cold due to the high fraction of EGR (25\%). Almost $40 \%$ of the 
chemical energy in the fuel is released within the jet (the premixed combustion). The chemical composition graph shows a thin sliver of precursors, equivalent to approximately $20 \mathrm{~g}$ per $\mathrm{kg}$ of fuel.

Point 2 corresponds to operation with maximum precursor formation. The details of the combustion event for Point 2 (see Figure 4) are shown in Figure 6. Maximum precursor formation for this condition corresponds to approximately $200 \mathrm{~g} / \mathrm{kg}$ of fuel. With $65 \%$ EGR and $\phi_{0}=0.2$, the combustion inside the jet is quite cold, reaching a maximum temperature of only $1600 \mathrm{~K}$. Heat release inside the jet is only $22 \%$ of the total available, limited by the small amount of oxygen entrained in the jet, since a significant fraction of the entrained gases are $\mathrm{CO}_{2}$ and $\mathrm{H}_{2} \mathrm{O}$. Ignition occurs almost at the same time as for Point 1 (Figure 5). However, oxygen depletion does not occur until $0.2 \mathrm{~ms}$ after ignition, as the lower temperature reduces the reactivity of the mixture.

Point 3 represents the high EGR smokeless combustion operation regime. Combustion details for Point 3 are shown in Figure 7, for 80\% EGR and $\phi_{0}=0.2$. In this case, the lack of oxygen caused by the extremely high EGR fraction keeps the combustion very cold. The temperature never exceeds $1000 \mathrm{~K}$ in the time period being analyzed. Lack of oxygen inside the jet also limits the chemical heat release to $2 \%$ of the total fuel energy. The combustion is cold enough that it produces a very low concentration of precursors (less than $10 \mathrm{~g} / \mathrm{kg}$ of fuel, not visible in the figure), and most of the fuel goes unreacted. The temperature is low enough that some oxygen remains beyond the $0.5 \mathrm{~ms}$ interval being analyzed, indicating that the soot precursors existing inside the jet may not be very effective producing soot, as the oxygen may react with the precursors before these have time to consolidate into soot [18].

Previous publications on low temperature combustion have described the "soot peninsula," a region in the T- $\phi$ diagram where combustion results in considerable soot emissions [7]. Figure 8 shows the soot peninsula, which spreads in temperature between $1600 \mathrm{~K}$ and $2600 \mathrm{~K}$, and down to about 2 in equivalence ratio. In addition to the soot peninsula, Figure 8 shows the path in T- $\phi$ space of Points 1, 2 and 3 (see Figure 4). The end of the path during the $0.5 \mathrm{~ms}$ of analysis is indicated by a dot. A dotted arrow then follows, indicating the likely path of the point as it proceeds along the fuel jet, where we have assumed that the fuel gets hotter and leaner as it progresses along the jet due to heat transfer, diffusion and reaction with other regions in the cylinder.

For Point 1 at $25 \%$ EGR, the path almost misses the soot peninsula due to the low equivalence ratio at the point of ignition, and therefore little soot production is expected at these operating conditions. This is in agreement with the low precursor concentration obtained from the chemical kinetic analysis (20 g/ $\mathrm{kg}$ fuel; Figure 4). If additional mixing could be achieved before the time of ignition, possibly by reducing the air temperature in the combustion chamber, the path of Point 1 would completely miss the soot peninsula, resulting in smokeless combustion. This is the principle of MK combustion [2], where enhanced mixing and low temperature result in long ignition timing, which permits relatively lean $(\phi<2)$ and smokeless combustion. While combustion at $\phi<2$ produces 
smokeless combustion, it may still produce high $\mathrm{NO}_{\mathrm{x}}$. More enhanced mixing (below $\phi=1$ ) is necessary for smokeless, low $\mathrm{NO}_{\mathrm{x}} \mathrm{MK}$ combustion.

The path of Point 2 ends at $\phi$ greater than 3 and at a relatively low temperature, as indicated by the dot in Figure 8. While the end point for the path of Point 2 is not inside the soot peninsula, it is in a region that makes considerable precursors [7]. In addition to this, the likely path as the fuel parcel proceeds along the jet (indicated by a dotted arrow in the figure) leads it directly into the soot peninsula, resulting in considerable production of soot.

For Point 3, the mixture remains very rich $(\phi>8)$ but also very cold $(\mathrm{T}<1000 \mathrm{~K})$. Under these conditions, it is unlikely that the fuel parcel can move into the soot peninsula as it travels along the fuel jet. In addition to this, the final composition of Point 3 includes oxygen (Figure 7), which reacts with any precursors being formed and slows down the progress of the fuel parcel toward the soot peninsula.

From the results presented in Figure 8 we can illustrate the two paths that have been previously demonstrated to avoid soot formation [13]. One is by greatly reducing the temperature through extensive use of EGR (smokeless rich combustion, as achieved for Point 3), and the other is by enhancing mixing to achieve combustion at low equivalence ratio (MK combustion, as could be achieved for Point 1 through additional mixing).

In addition to the runs for specific points at a fixed fueling rate, we have also analyzed the effect of multiple fueling rates on soot precursor production. Figure 9 shows concentration of precursors in grams per gram of fuel as a function of air-fuel ratio, for multiple lines corresponding to different fueling rates (different values of $\phi_{0}$ ). The figure shows that for all the fueling rates there is an air-fuel ratio that corresponds to maximum soot precursors, and the maximum level of soot precursors remains fairly constant for all the fueling rates being considered, at about $200 \mathrm{~g} / \mathrm{kg}$ of fuel. At the high fueling rates $\left(\phi_{0}>0.6\right)$ no peak in soot precursors is observed because the curve reaches the stoichiometric line before the peak soot concentration is reached.

In Figure 9, a different soot precursor line is necessary for each fueling rate. However, we have been able to collapse the lines for all the fueling rates onto a single line by using an appropriate choice for the $\mathrm{x}$-axis variable. Both temperature after ignition and equivalence ratio at the time of ignition $\left(\phi_{\mathrm{i}}\right)$ can be used as $\mathrm{x}$-axis variables to obtain a single line that yields soot precursors for all fueling rates. This is illustrated in Figures 10 and 11. Figure 10 shows soot precursors in grams per gram of fuel as a function of temperature after ignition. All the points included in Figure 9 are included in Figure 10, with the symbols indicating the fueling rate that corresponds to each point. The figure shows that all the lines for the different fueling rates shown in Figure 9 now collapse onto a single line, and soot precursors can be directly predicted from the value of the temperature after ignition. Figure 10 shows that peak soot concentration is always reached at $1600 \mathrm{~K}$, and soot emissions drop to zero when the temperature after ignition approaches $900 \mathrm{~K}$. 
Soot precursors for multiple fueling rates can also be collapsed onto a single line if equivalence ratio at the time of ignition $\left(\phi_{\mathrm{i}}\right)$ is used as the $\mathrm{x}$-axis variable. This is shown in Figure 11, where the symbols again indicate the fueling rate corresponding to each point. The figure shows that peak soot emissions are obtained at $\phi_{\mathrm{i}}$ slightly above 3 , and soot emissions drop to nearly zero as $\phi_{\mathrm{i}}$ drops below 2 . The definition of $\phi_{\mathrm{i}}$ used here is very similar to the equivalence ratio at lift-off length, $\phi(\mathrm{H})$, previously defined in diesel injection studies [22], since the lift-off length is defined as the point where chemical reaction starts. For this reason, many results previously obtained for $\phi(\mathrm{H})$ also apply for $\phi_{\mathrm{i}}$ : diesel soot emissions correlate well with $\phi(\mathrm{H})$, and smokeless combustion is obtained when $\phi(\mathrm{H})<2$ [13].

\section{Sensitivity Analysis}

In this section we analyze the sensitivity of the results for soot precursor as the two most important model parameters are modified: gas temperature inside the cylinder and the characteristic mixing time $(\tau)$. The results are presented in Figures 12-15. Figure 12 shows soot precursors as a function of temperature after ignition, for three gas temperatures inside the combustion chamber: $1000 \mathrm{~K}, 1100 \mathrm{~K}$ and $1200 \mathrm{~K}$. All previous results in this paper use $1000 \mathrm{~K}$. Figure 12 includes results for all the fueling rates analyzed and displayed in Figure 9. However, the fueling rates are not identified with symbols in Figure 12 for increased clarity. The figure shows that, once again, the points for each of the three gas temperatures collapse onto a single line for all fueling rates, as previously observed for $1000 \mathrm{~K}$ (Figure 10). However, gas temperature has a significant effect on soot precursors, as these tend to increase considerably as the gas temperature increases. Peak soot precursor concentration increases from $200 \mathrm{~g} / \mathrm{kg}$ of fuel for $1000 \mathrm{~K}$ gas to $330 \mathrm{~g} / \mathrm{kg}$ at $1200 \mathrm{~K}$. Only for the lower combustion temperatures (less than 1300 $\mathrm{K})$, the three lines collapse onto a single line, and smokeless combustion is obtained for the three gas temperatures as the fraction of EGR increases and the mixture becomes stoichiometric at low fueling rates. In the high temperature end of the figure it is observed that combustion at the coldest gas temperature $(1000 \mathrm{~K})$ results in higher combustion temperature $(2200 \mathrm{~K})$ and lower soot emissions $(10 \mathrm{~g} / \mathrm{kg}$ of fuel $)$. This is because the lower temperature of the gases reduces the reactivity of the mixture and results in more gas entrainment into the jet before the time of ignition. As previously described, additional oxygen inside the jet reduces the concentration of precursors, and produces smokeless combustion $(\mathrm{MK})$ when $\phi_{\mathrm{i}}<2$. Additional oxygen also increases the temperature of combustion, as more of the available heat release in the fuel is released before the oxygen is depleted.

The sensitivity of soot precursors to gas temperature in the combustion chamber is shown again in Figure 13, this time with the equivalence ratio at the time of ignition $\left(\phi_{\mathrm{i}}\right)$ as the $\mathrm{x}$-axis variable. Figure 13 shows that the curves for the different gas temperatures shift to higher equivalence ratios as the temperature is increased. This is again due to the increased reactivity of the fuel with the higher temperature air that limits the mixing that can occur before ignition. 
Figures 14 and 15 show the sensitivity of soot precursors to the characteristic mixing time, $\tau$. As previously discussed, $\tau$ describes the mixing process in this model. A small $\tau$ indicates that the fuel jet mixes rapidly with the surrounding air, and a large $\tau$ represents slow mixing (see Equation 1). Figure 14 shows soot precursors in grams per gram of fuel as a function of temperature after ignition, for three values of $\tau$ separated by factors of 2 $\left(5 \times 10^{-5} \mathrm{~s}, 10^{-4} \mathrm{~s}\right.$ and $\left.2 \times 10^{-4} \mathrm{~s}\right)$. All previous calculations in this paper use $\tau=10^{-4} \mathrm{~s}$. The figure shows that the peak precursor production drops considerably as $\tau$ is reduced, as improved mixing tends to reduce soot production. As previously observed, all low temperature combustion cases ( $\mathrm{T}$ under $1300 \mathrm{~K}$ ) have the same soot emissions regardless of the mixing rate.

Figure 15 shows once again soot precursors in grams per gram of fuel as a function of temperature after ignition, for three values of $\tau$. However, in Figure 15 the three values of $\tau$ are separated by factors of $10\left(\tau=10^{-5} \mathrm{~s}, 10^{-4} \mathrm{~s}\right.$ and $\left.10^{-3} \mathrm{~s}\right)$. At these conditions, the slow mixing case $\left(\tau=10^{-3} \mathrm{~s}\right)$ produces considerably more precursors than the base case, but the plot keeps the same general shape as observed in Figure 14. For the very fast mixing case ( $\tau=10^{-5} \mathrm{~s}$ ), the temperature (and therefore the level of precursors) is quickly reduced by the extremely high level of mixing. Interestingly, this corresponds qualitatively to the experimentally observed reduction in soot seen in MK type combustion systems that utilize higher than normal mixing rates through enhanced swirl.

\section{Conclusions}

We have developed a model of the diesel fuel injection process for application to analysis of low temperature non-sooting combustion. The model uses a simplified mixing correlation and detailed chemical kinetics, and analyzes a parcel of fuel as it moves along the fuel jet, from injection into evaporation and ignition. The model predicts chemical composition and soot precursors, and is applied at conditions that result in low temperature non-sooting combustion. Production of soot precursors is the first step toward production of soot, and modeling precursor production is expected to give insight into the overall evolution of soot inside the engine. From these analyses we conclude:

1. Soot precursors are low at the low EGR cases. Precursors then increase rapidly as the EGR is increased, reaching a maximum and then decreasing rapidly to near zero as the mixture approaches stoichiometric conditions. These results are consistent with the behavior observed in experiments conducted at Toyota.

2. Two paths to achieve non-sooting combustion are investigated. The first is smokeless rich combustion and it is the result of restricting the amount of oxygen entrained into the jet to reduce the combustion temperature to very low levels. The second is modulated kinetics, and it is obtained by increasing the rate of mixing and reducing the operating temperature so that ignition does not occur until the equivalence ratio is low (less than 2). 
3. Soot precursors for all the fueling rates considered can be collapsed onto a single curve if the precursors are expressed as a function of the temperature after ignition, or as a function of the equivalence ratio at the time of ignition. These two variables are recognized as important parameters for characterizing low temperature non-sooting combustion.

4. Parametric analysis has evaluated the sensitivity of soot precursors to the two most important model parameters: gas temperature in the combustion chamber and characteristic mixing time. The results show that increasing temperature and reducing the rate of mixing tend to increase the equivalence ratio at the time of ignition, considerably increasing the soot precursor production.

5. This model has been successful in describing many of the observed characteristics of low temperature combustion. The model provides a chemical kinetic description of low temperature diesel combustion that improves our understanding of this clean and efficient regime of operation.

\section{Acknowledgments}

This project is funded by DOE, Office of FreedomCAR and Vehicle Technologies, Gurpreet Singh and Steve Goguen, program managers. Work performed under the auspices of the U.S. Department of Energy by University of California, Lawrence Livermore National Laboratory under Contract W-7405-ENG-48.

\section{References}

1. Sasaki, S., Ito, T., and Iguchi, S., 2000, "Smoke-less Rich Combustion by Low Temperature Oxidation in Diesel Engines," Proceedings of the $9^{\text {th }}$ Aachener Kolloquium Fahrzeug- und Motorentechnik 2000, Aachen, Germany.

2. Kimura, S., Matsui, Y., and Koike, M., 1998, "New Combustion Concept for Simultaneous Reduction of NOx and Particulate Emissions from Small DI Diesel Engines," Proceedings of the 1998 FISITA Congress, Paris, France.

3. Epping, K., Aceves, S.M., Bechtold, R.L., and Dec, J.E., 2002, "The Potential of HCCI Combustion for High Efficiency and Low Emissions," SAE Paper 200201-1923.

4. Sasaki, S., Kobayashi, N., Hashimoto, Y., Tanaka, T., and Hirota, S., 2002, "A New Combustion Concept for Clean Diesel System with DPNR," MTZ Worldwide, Vol. 63, No. 10, pp. 2-8.

5. Kimura, S., Aoki, O., Kitahara, Y., and Aiyoshizawa, E., 2001, Ultra-Clean

Combustion Technology Combining a Low-Temperature and Premixed 
Combustion Concept for Meeting Future Emission Standards," SAE Paper 200101-0200.

6. Kimura, S., Ogawa, H., Matsui, Y., and Enomoto, Y., 2002, “An Experimental Analysis of Low-Temperature and Premixed Combustion for Simultaneous Reduction of Nox and Particulate Emissions in Direct Injection Diesel Engines," International Journal of Engine Research, Vol. 3, No. 4, pp. 249-259.

7. Akihama, K., Takatori, Y., Inagaki, K., Sasaki, S., and Dean, A.M., 2001, "Mechanism of the Smokeless Rich Diesel Combustion by Reducing Temperature," SAE Paper 2001-01-0655.

8. Bianchi, G.M., Cazzoli, G., Pelloni, P., and Corcione, F.E., 2002, "Numerical Study Towards Smoke-Less and NOx-Less Diesel Engine Combustion," SAE Paper 2002-01-1115.

9. Narushima, T., Morishima, A., Morikawi, H., Kusaka, J., and Daisho, Y., 2003, "Experimental and Numerical Studies on Soot Formation in Fuel-Rich Mixture," SAE Paper 2003-01-1850.

10. Wagner, R.M., Green, J.B., Dam, T.Q., Edwards, K.D., and Storey, J.M., 2003, "Simultaneous Low Engine-Out NOx and Particulate Matter with Highly Diluted Diesel Combustion," SAE Paper 2003-01-0262.

11. Pickett, L., and Siebers, D.L., 2003, "Fuel Effects on Soot Processes of Fuel Jets at DI Diesel Conditions," SAE Paper 2003-01-3080.

12. Sluder, C.S., Wagner, R.M., Lewis, S.A., and Storey, J.M.E., 2004, "Exhaust Chemistry of Low-NOx, Low-PM Diesel Combustion," SAE Paper 2004-010114.

13. Pickett, L., and Siebers, D.L., 2004, "Non-sooting, Low Flame Temperature Mixing-Controlled DI Diesel Combustion,” SAE Paper 2004-01-1399.

14. Frenklach, M., and Wang, H., 1994, "Detailed Mechanism and Modeling of Soot Particle Formation," in Soot Formation in Combustion: Mechanisms and Models (H. Bockhorn, Ed.), Springer Series in Chemical Physics, Vol. 59, SpringerVerlag, Berlin, pp. 162-190.

15. Dec, J.E., 1997, "A Conceptual model of DI Diesel Combustion Based on LaserSheet Imaging," SAE Paper 970873.

16. Kosaka, H., Aizawa, T., and Kamimoto, T., 2004, "Two-Dimensional Imaging of Ignition and Soot Formation Processes in a Diesel Flame," Submitted to the International Journal of Engine Research.

17. Bayer, J., and Foster, D., 2003, “Zero-Dimensional Soot Modeling," SAE Paper 2003-01-1070.

18. Mueller, C.J., Pitz, W.J., Pickett, L.M., Martin, G.C., Siebers, D.L., Westbrook, C.K., 2003, "Effects of Oxygenates on Soot Processes in DI Diesel Engines: Experiments and Numerical Simulations," SAE Paper 2003-01-1791.

19. Flynn, P. F., Hunter, G. L., Durrett, R. P., Farrell, L. A., and Akinyemi, W. C., 2000, "Minimum Engine Flame Temperature Impacts on Diesel and SparkIgnition Engine $\mathrm{NO}_{\mathrm{x}}$ Production," SAE Paper 2000-01-1177.

20. Heywood, J. B., Internal Combustion Engine Fundamentals, McGraw-Hill, Inc., New York, NY, 1988. 
21. Curran, H.J., Gaffuri, P., Pitz, W.J., and Westbrook, C.K., 1998, “A Comprehensive Modeling Study of n-Heptane Oxidation," Combustion and Flame, Vol. 114 No. 1-2, pp. 149-177.

22. Pickett, L., and Siebers, D.L., 2002, "An Investigation of Diesel Soot Formation Processes Using Micro-Orifices," Proceedings of the Combustion Institute, Vol. 29, pp. 655-662. 
Table 1. Parameters used in the analysis. For gas temperature and characteristic mixing time, the table lists a base case value as well as a range of operation used for sensitivity analysis.

\begin{tabular}{|l|l|}
\hline \multicolumn{1}{|c|}{ Parameter } & \multicolumn{1}{c|}{ Value } \\
\hline Gas temperature inside cylinder & $1000 \mathrm{~K}(1000-1200 \mathrm{~K})$ \\
\hline Gas pressure inside cylinder & $83 \mathrm{bar}$ \\
\hline Fuel injection temperature & $400 \mathrm{~K}$ \\
\hline Fuel evaporation temperature & $650 \mathrm{~K}$ \\
\hline Pseudo specific heat of diesel fuel & $2720 \mathrm{~J} / \mathrm{kg} \mathrm{K}$ \\
\hline Chemical surrogate for diesel fuel & n-heptane \\
\hline Number of species in mechanism & 544 \\
\hline Precursors & $\begin{array}{l}\text { ethylene }\left(\mathrm{C}_{2} \mathrm{H}_{4}\right) \\
\text { acetylene }\left(\mathrm{C}_{2} \mathrm{H}_{2}\right)\end{array}$ \\
& $\begin{array}{l}\text { allene }\left(\mathrm{C}_{3} \mathrm{H}_{4-\mathrm{a}}\right) \\
\text { propyne }\left(\mathrm{C}_{3} \mathrm{H}_{4-\mathrm{p}}\right)\end{array}$ \\
& allyl $\left(\mathrm{C}_{3} \mathrm{H}_{5-\mathrm{a}}\right)$ \\
\hline Characteristic mixing time, $\tau$ & $0.0001 \mathrm{~s}(0.001-$ \\
& $\left.0.00001 \mathrm{~s}^{2}\right)$ \\
\hline Equivalence ratio at zero EGR, $\phi_{\mathrm{o}}$ & $0.1-1$ \\
\hline EGR fraction & $0-0.9$ \\
\hline
\end{tabular}




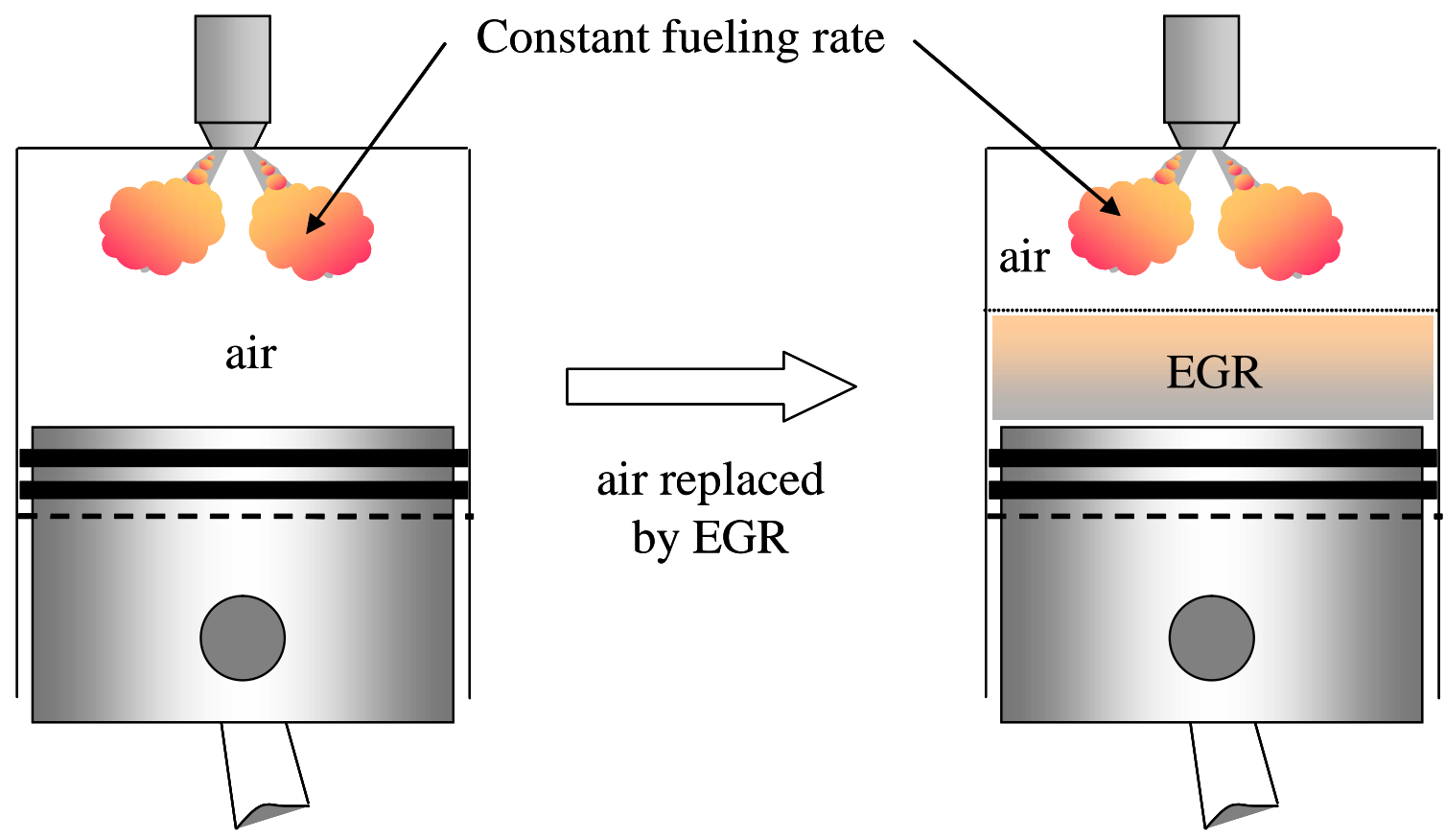

Figure 1. Sequence of engine operating conditions being analyzed. The air-fuel ratio in the engine is reduced at a constant fueling rate by replacing some of the fresh intake air with exhaust gases. Air and EGR are shown separately in the figure in the right only for illustration purposes, since air and EGR are assumed to be well mixed. 


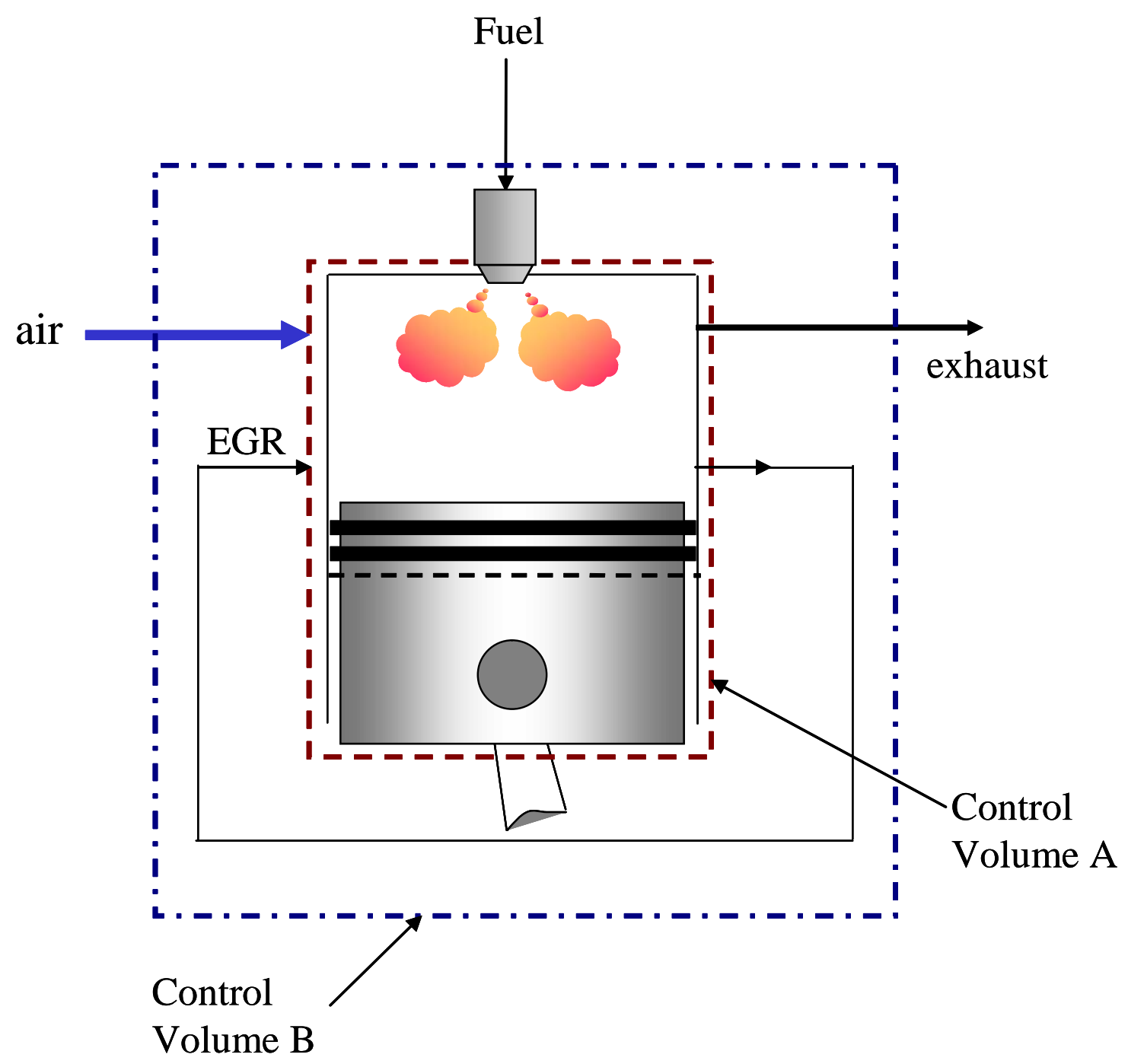

Figure 2. The two control volumes (Control volume A and Control Volume B) used for determining gas composition inside the combustion chamber. 


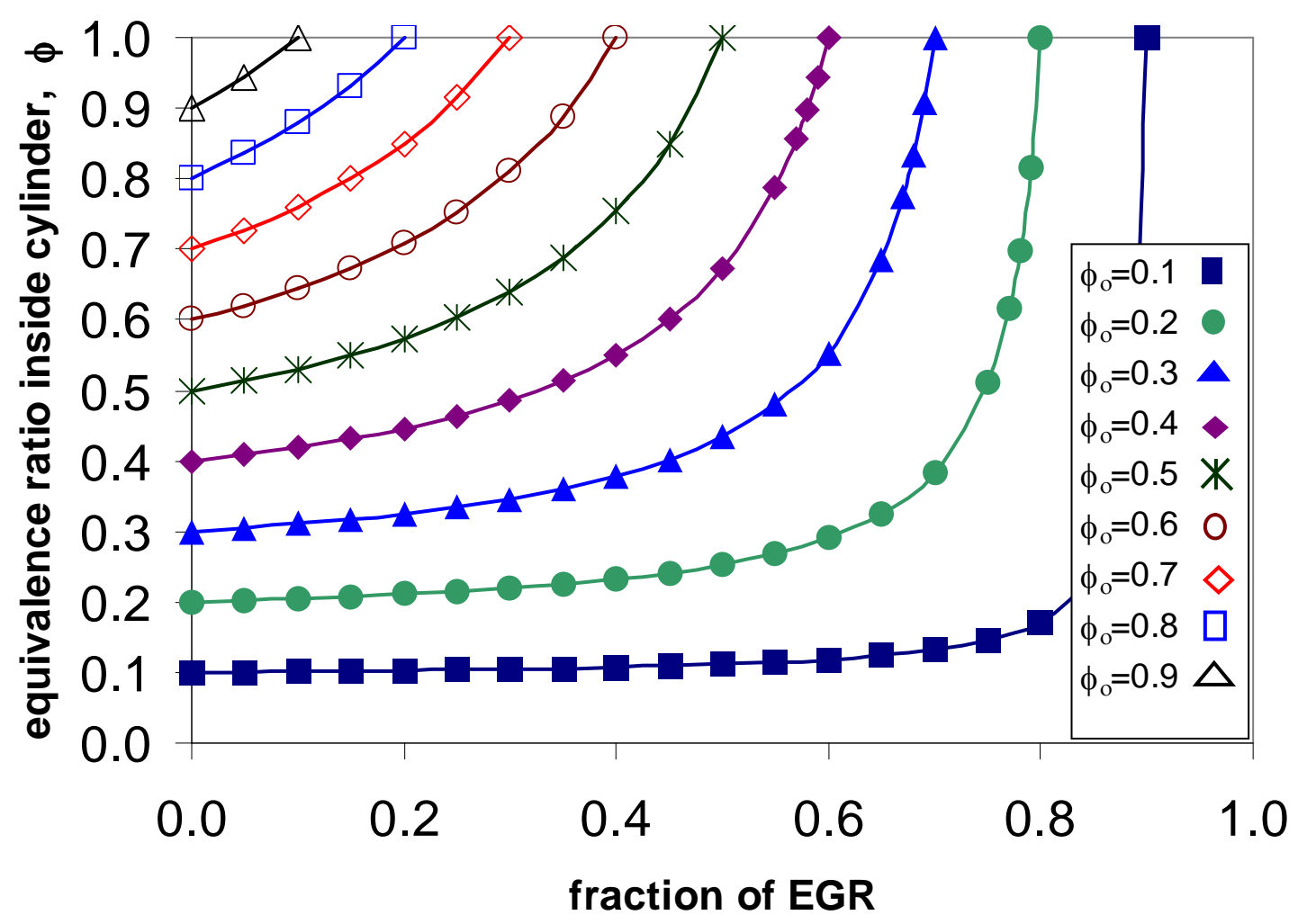

Figure 3. Equivalence ratio inside the cylinder $\phi$ as a function of fraction of EGR, for multiple lines corresponding to different values of $\phi_{0}$, for $n$-heptane. 


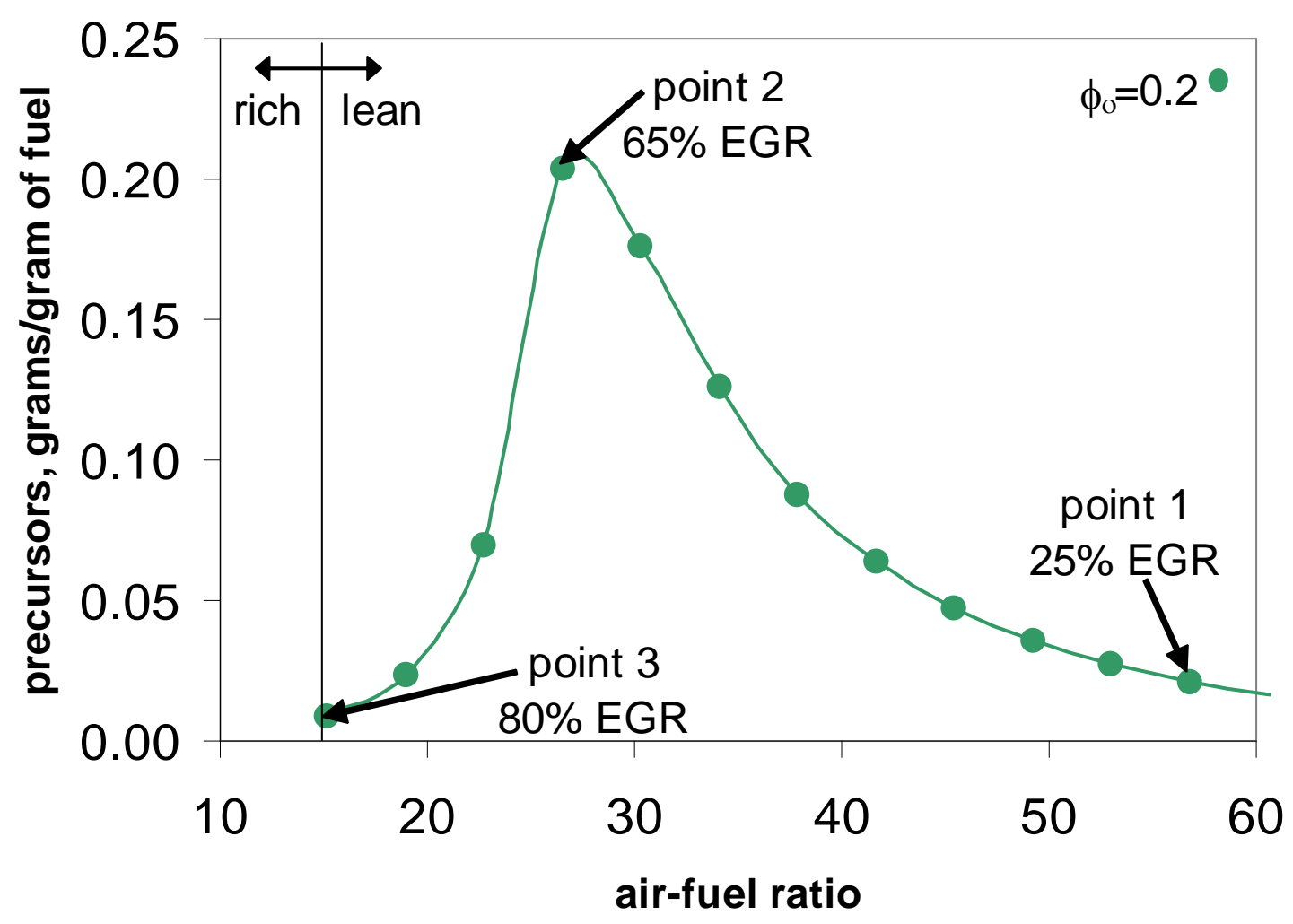

Figure 4. Soot precursors generated during fuel combustion in grams per gram of fuel, as a function of the air-fuel ratio, for $\phi_{0}=0.2$. All the points on the line have the same fueling rate $\left(\phi_{0}=\right.$ constant), and the air-fuel ratio in the figure is changed by increasing the fraction of EGR, according to Equation (5). The level of EGR is indicated by the dots in the figure, each representing a 5\% change in EGR fraction. The figure also has three points marked on it (Points 1,2 and 3). Combustion for these three points is described in detail later in the paper. 

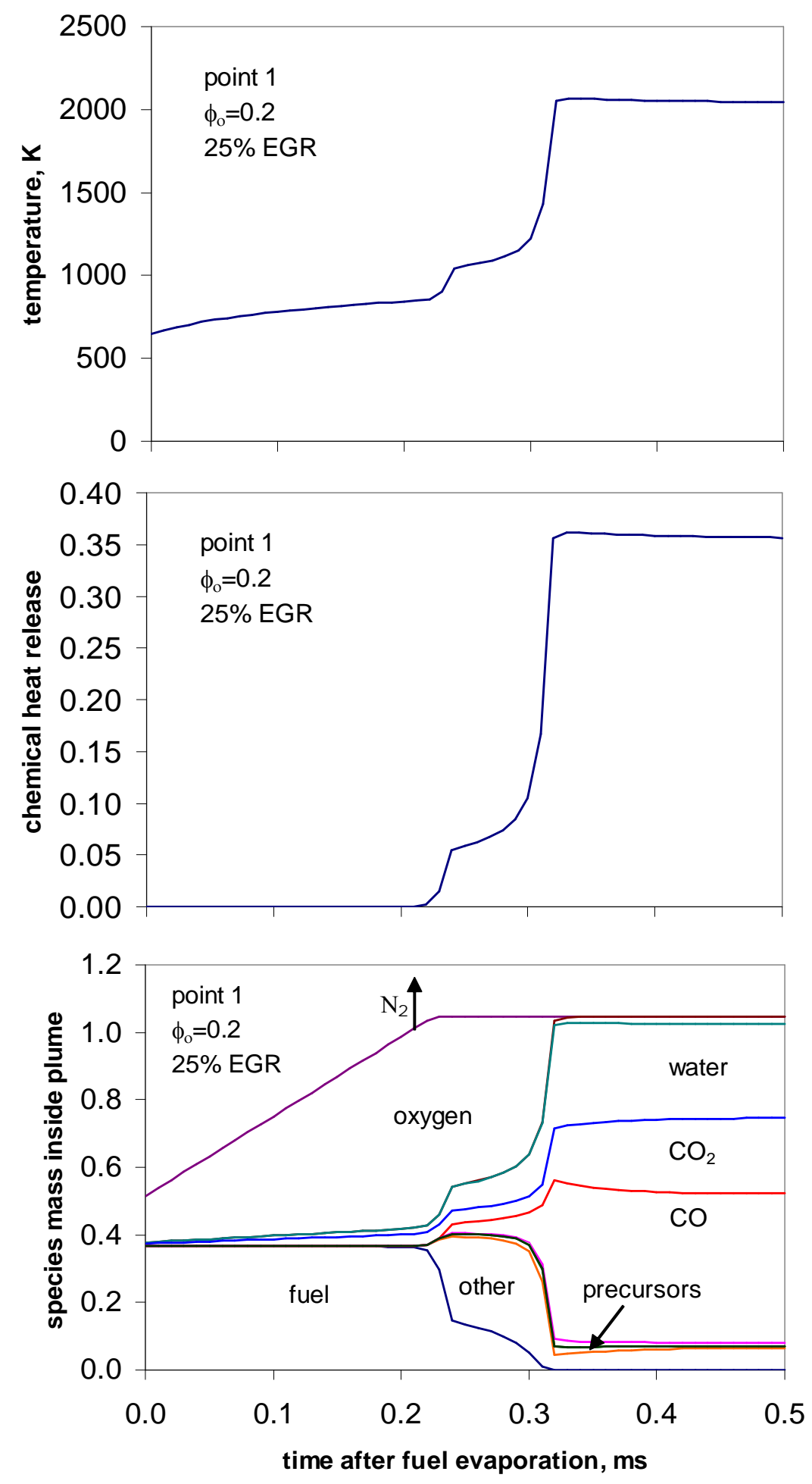

Figure 5. Combustion details for operating Point 1 (see Figure 4), showing temperature (upper graph), chemical heat release, expressed as a fraction of the total available chemical energy in the fuel (middle graph) and species mass composition inside the jet (lower graph). Mass composition is expressed in arbitrary units, considering that the total mass in the fuel parcel is equal to 1 at the moment of fuel evaporation. 

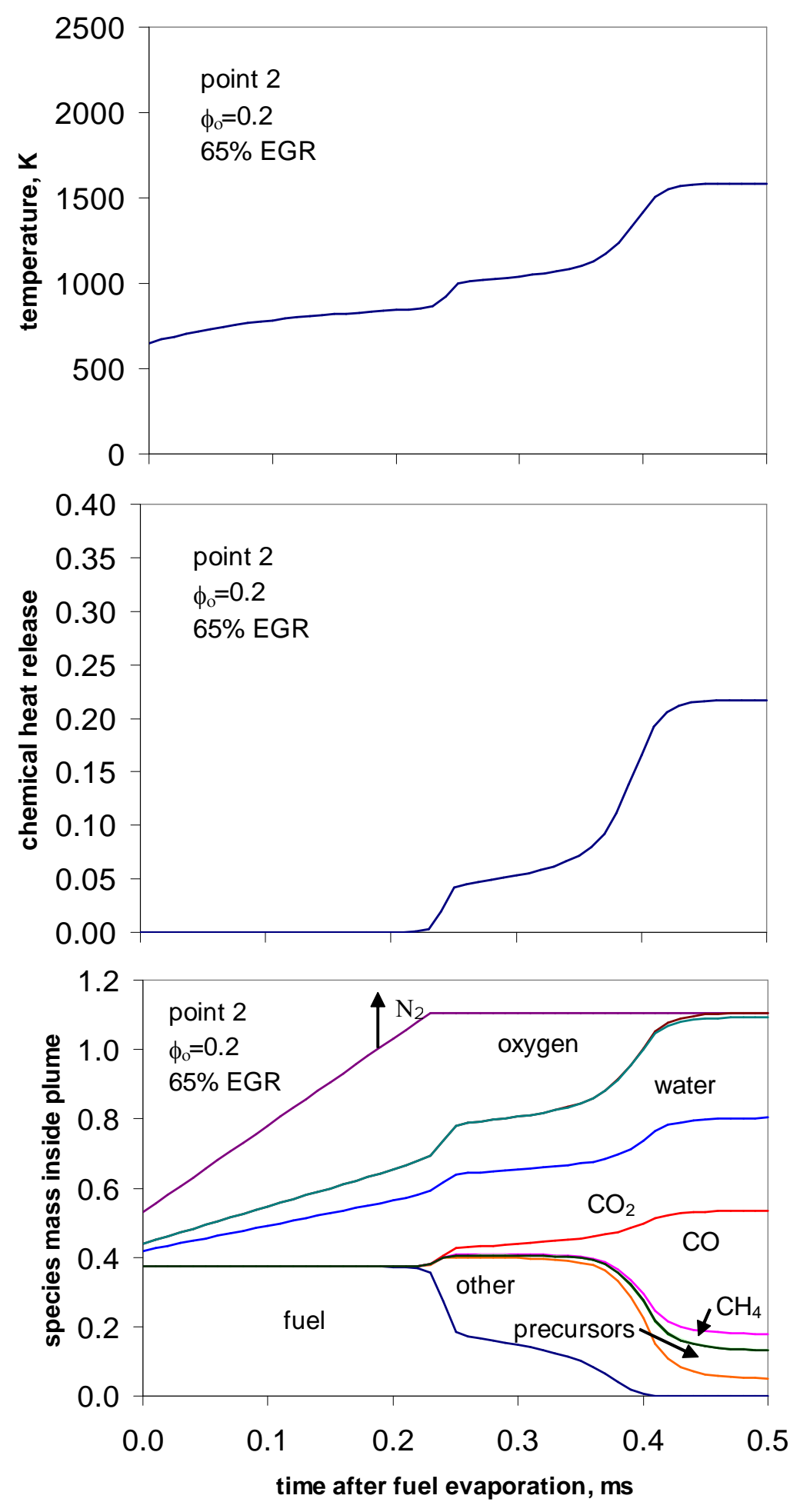

Figure 6. Combustion details for operating Point 2 (see Figure 4), showing temperature (upper graph), chemical heat release, expressed as a fraction of the total available chemical energy in the fuel (middle graph) and species mass composition inside the jet (lower graph). Mass composition is expressed in arbitrary units, considering that the total mass in the fuel parcel is equal to 1 at the moment of fuel evaporation. 

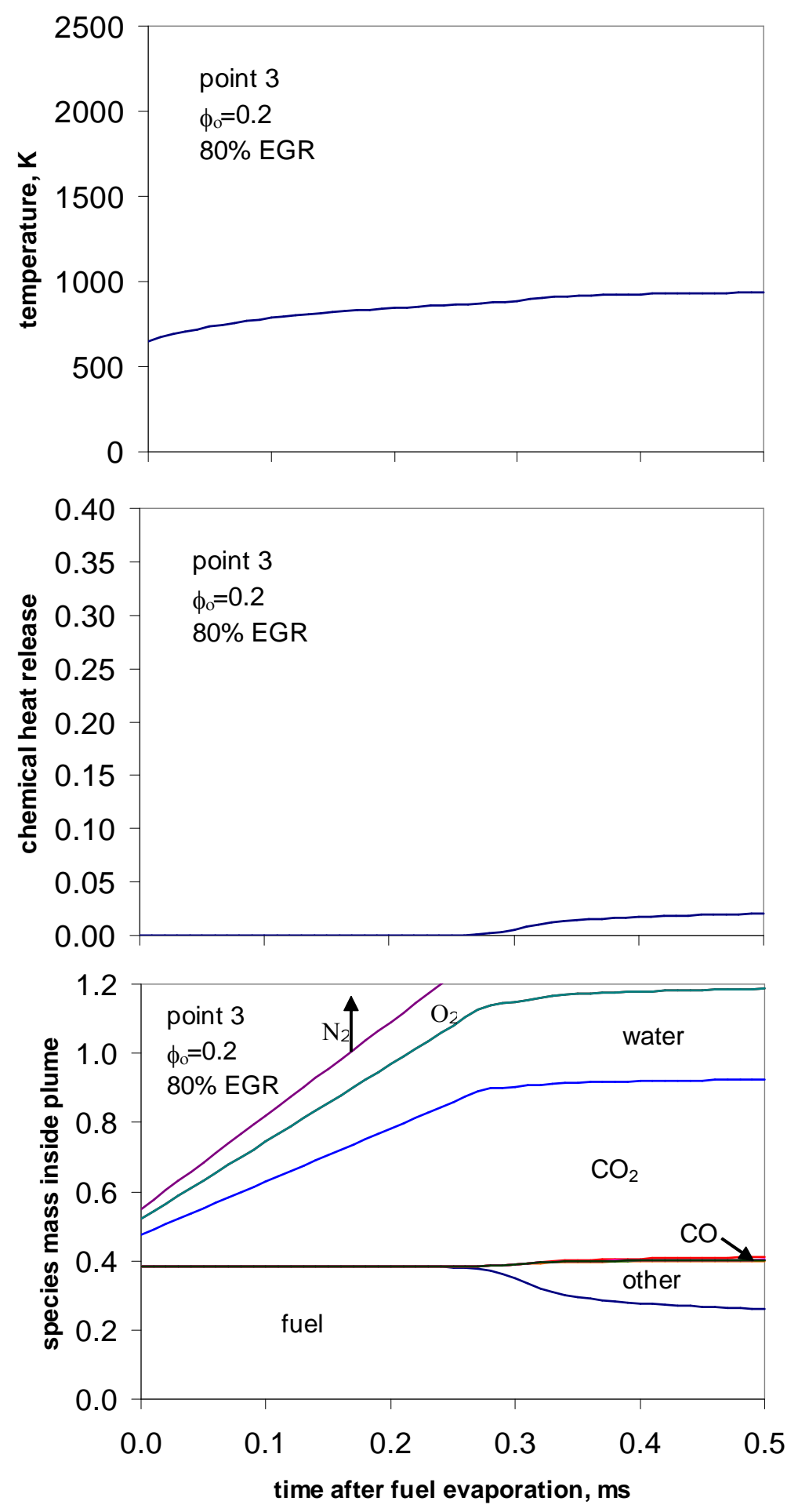

Figure 7. Combustion details for operating Point 3 (see Figure 4), showing temperature (upper graph), chemical heat release, expressed as a fraction of the total available chemical energy in the fuel (middle graph) and species mass composition inside the jet (lower graph). Mass composition is expressed in arbitrary units, considering that the total mass in the fuel parcel is equal to 1 at the moment of fuel evaporation. 


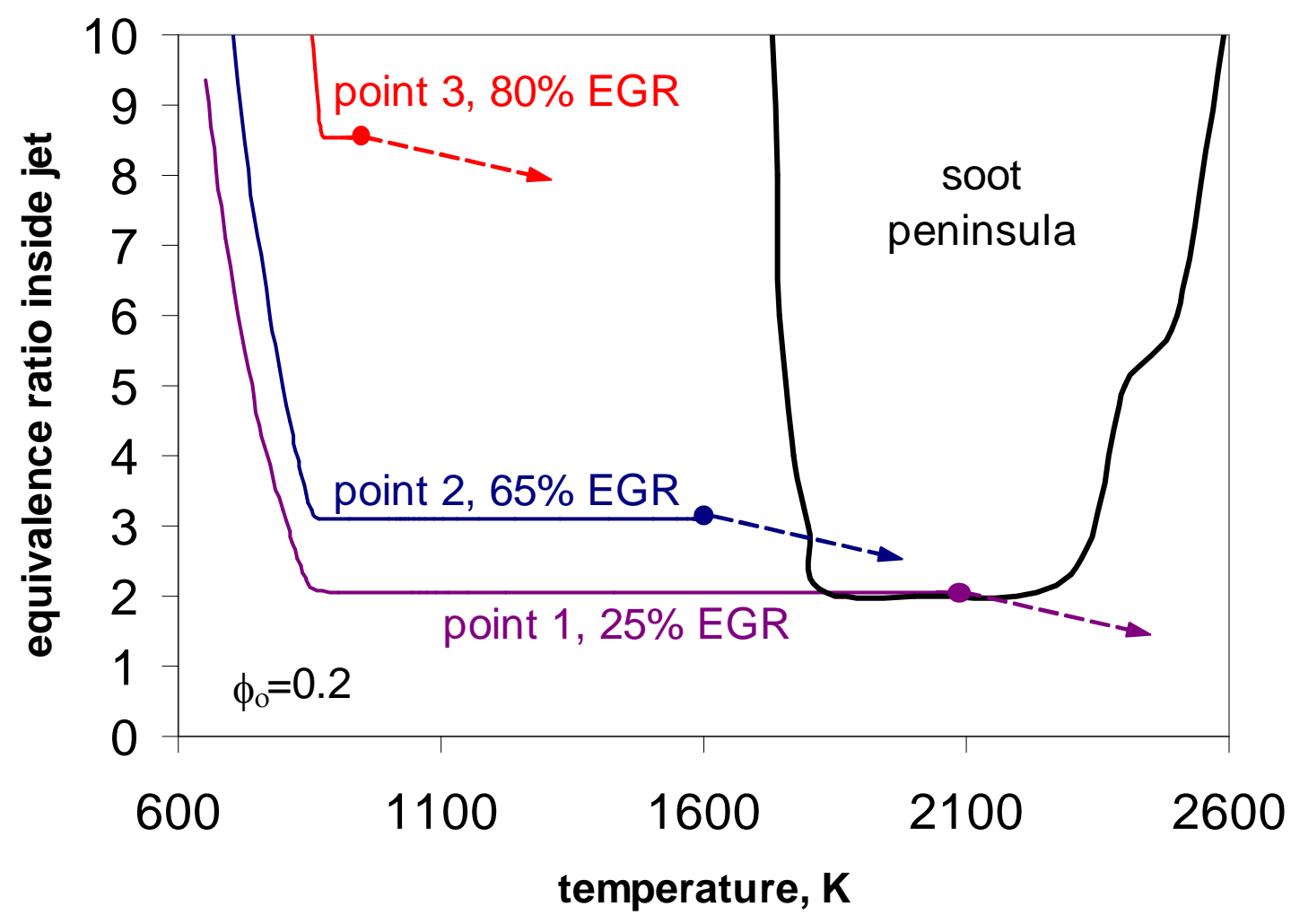

Figure 8. Path in T- $\phi$ space described by Points 1, 2 and 3 (see Figure 4). The end of the path during the $0.5 \mathrm{~ms}$ of analysis is indicated by a dot. A dotted arrow then follows, indicating the likely path of the point as it proceeds along the fuel jet. The figure also shows the "soot peninsula," a region in the T- $\phi$ diagram where combustion results in considerable soot emissions [7]. 


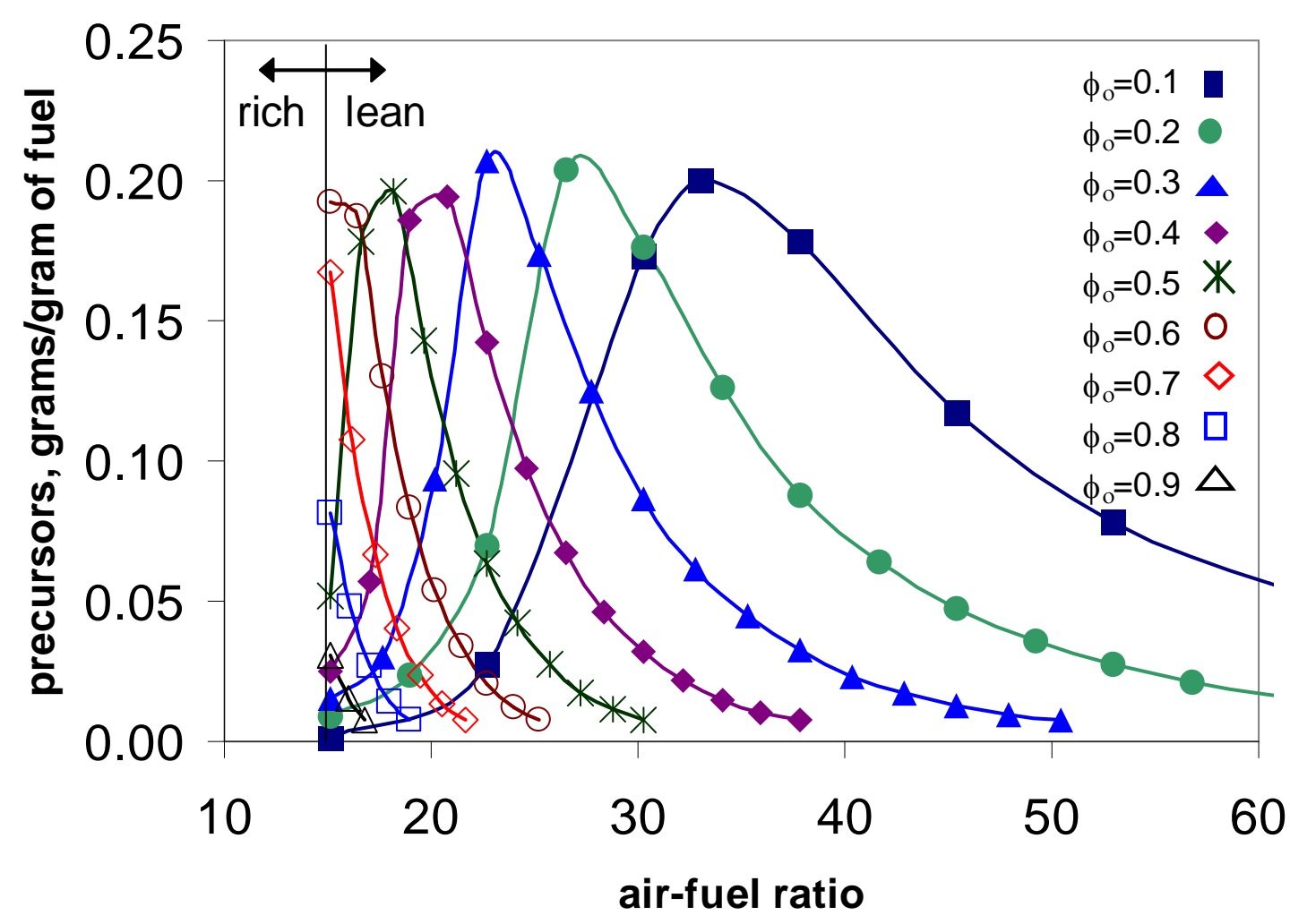

Figure 9. Concentration of precursors in grams per gram of fuel as a function of air-fuel ratio, for multiple lines corresponding to different fueling rates (different values of $\phi_{o}$ ). 


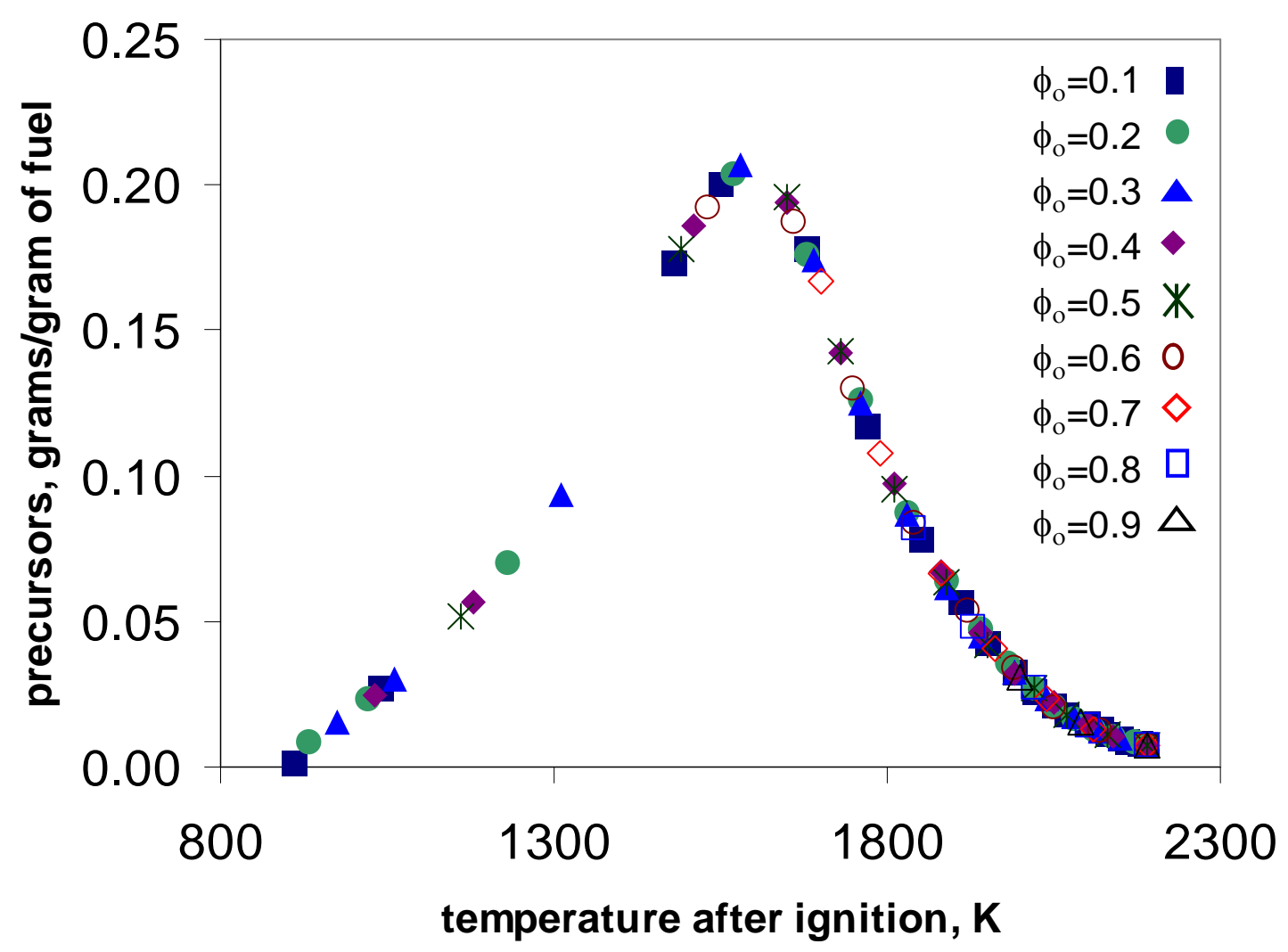

Figure 10. Soot precursors in grams per gram of fuel as a function of temperature after ignition, with multiple fueling rates (multiple values of $\phi_{0}$ ), indicated by the symbols. 


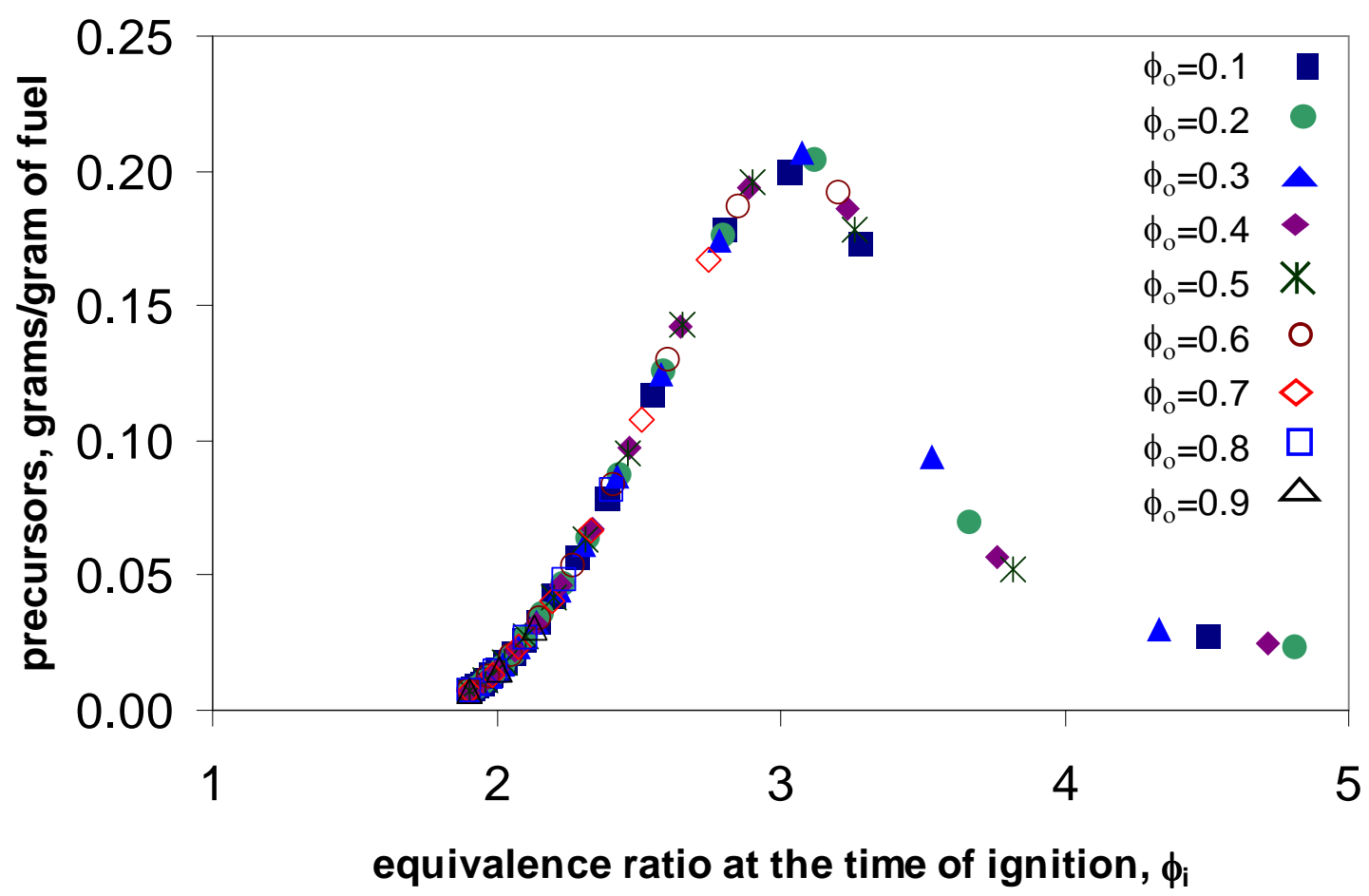

Figure 11. Soot precursors in grams per gram of fuel as a function of equivalence ratio after ignition $\left(\phi_{\mathrm{i}}\right)$, with multiple fueling rates (multiple values of $\phi_{\mathrm{o}}$ ), indicated by the symbols. 


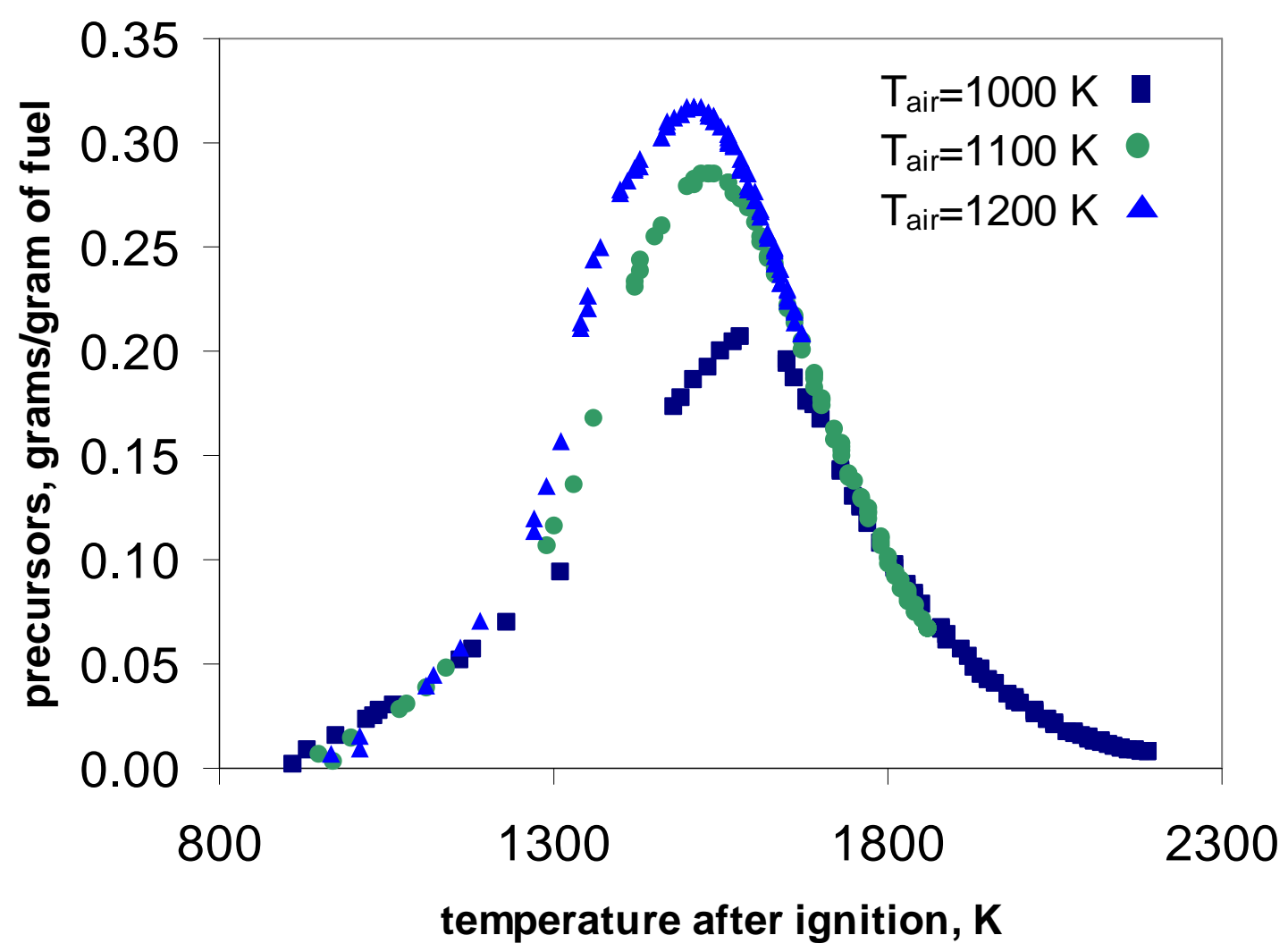

Figure 12. Soot precursors as a function of temperature after ignition, for three gas temperatures inside the combustion chamber: $1000 \mathrm{~K}, 1100 \mathrm{~K}$ and $1200 \mathrm{~K}$. 


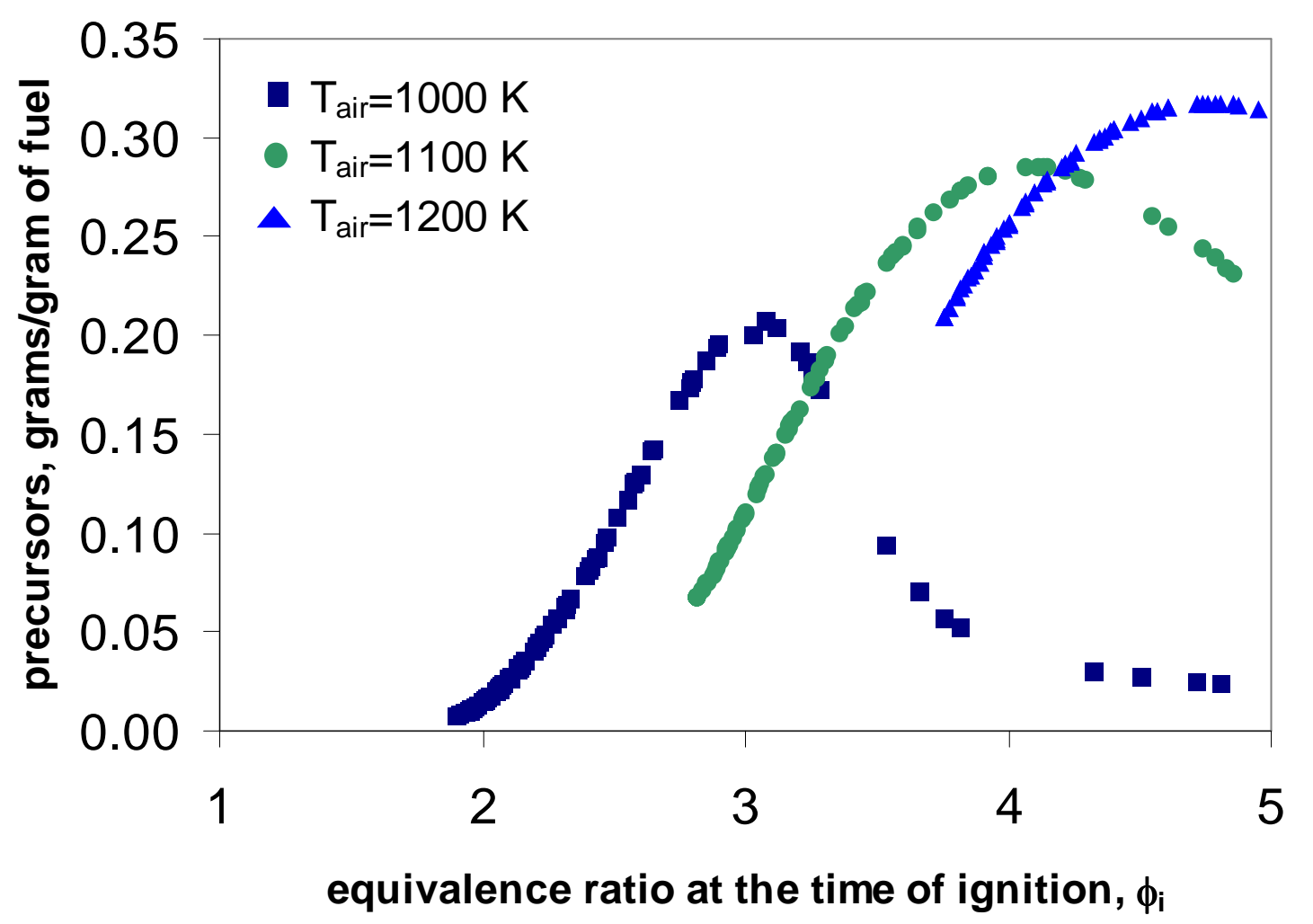

Figure 13. Soot precursors as a function of equivalence ratio at the time of ignition, for three gas temperatures inside the combustion chamber: $1000 \mathrm{~K}, 1100 \mathrm{~K}$ and $1200 \mathrm{~K}$. 


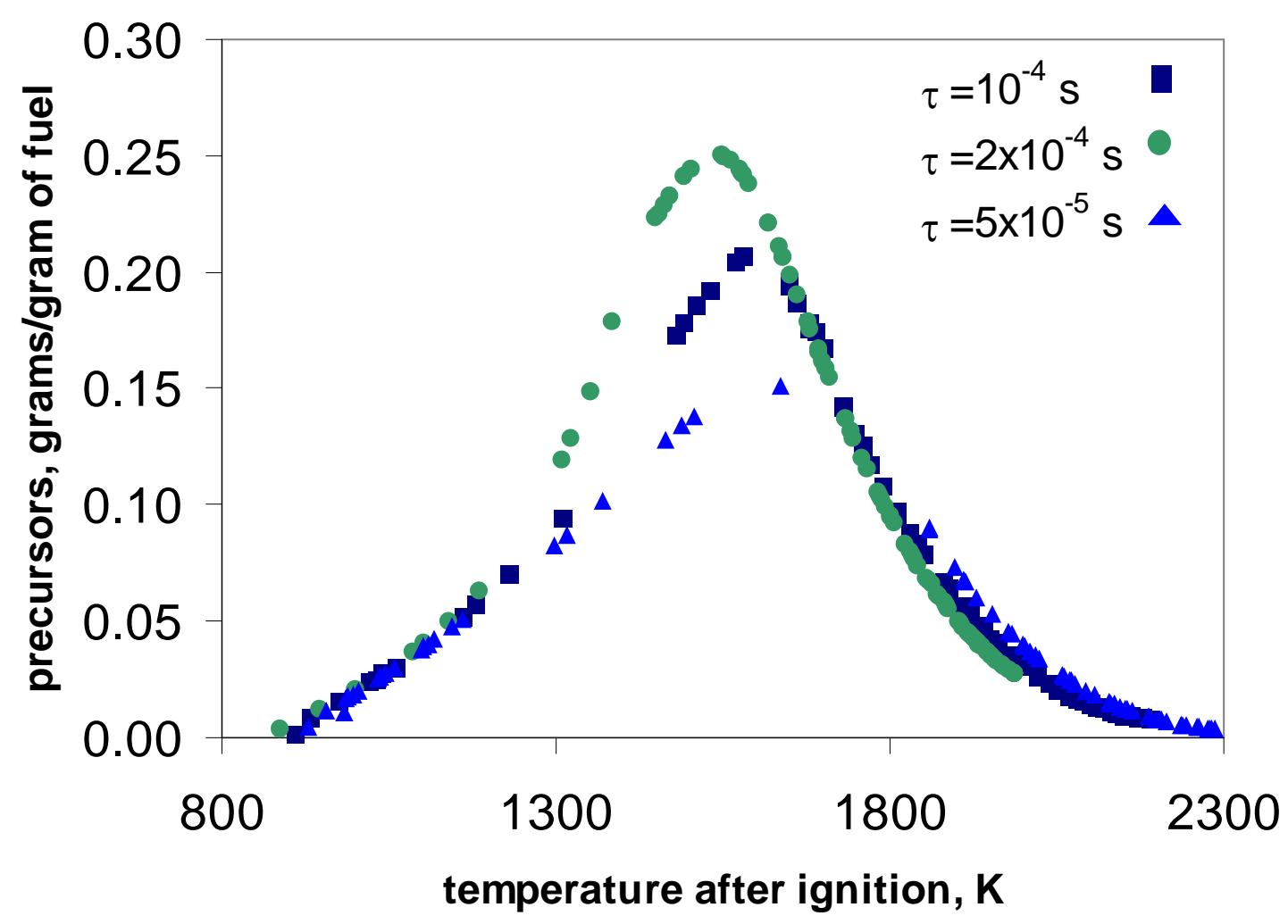

Figure 14. Soot precursors in grams per gram of fuel as a function of temperature after ignition, for three values of $\tau$ separated by factors of $2\left(5 \times 10^{-5} \mathrm{~s}, 10^{-4} \mathrm{~s}\right.$ and $\left.2 \times 10^{-4} \mathrm{~s}\right)$. 


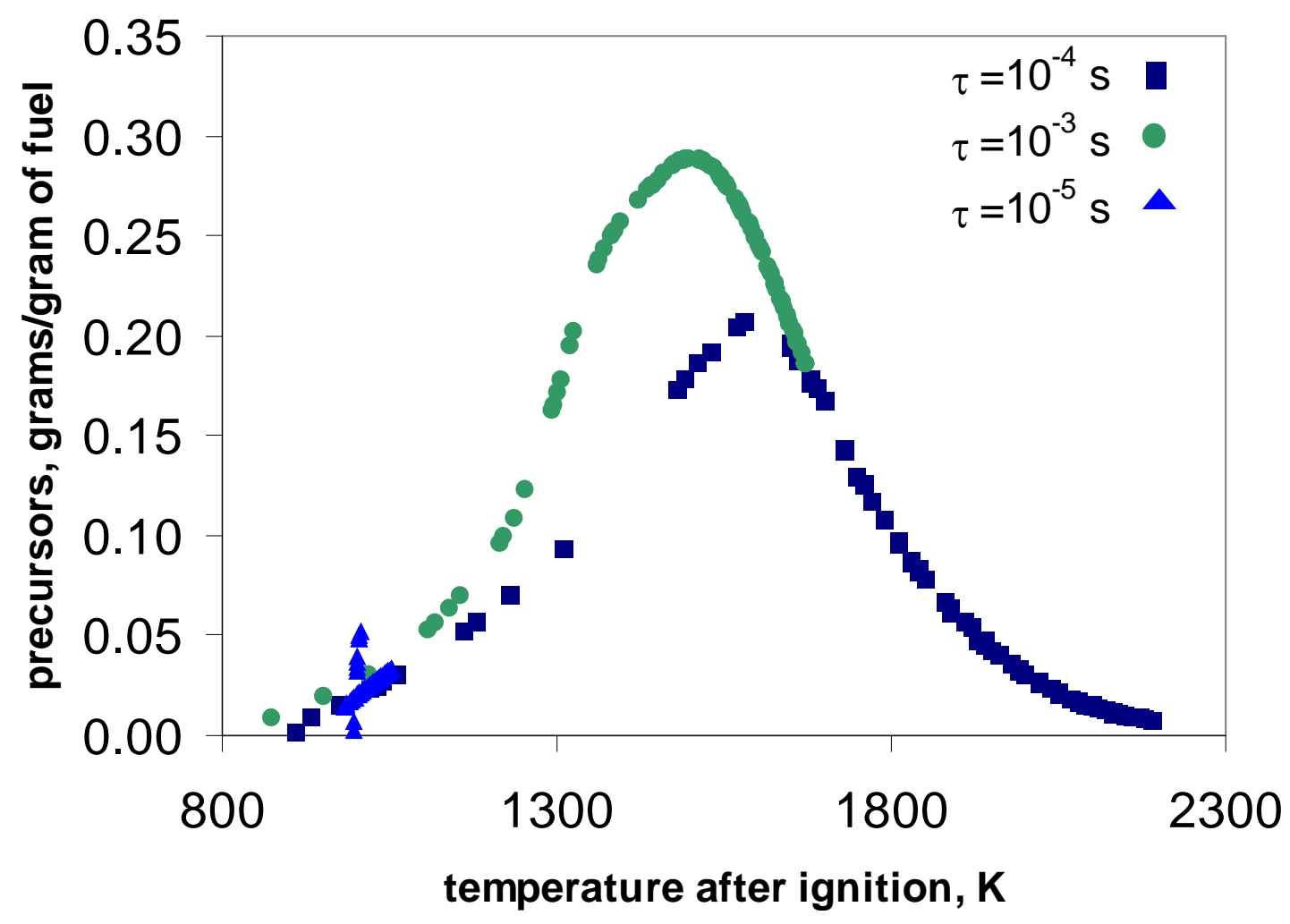

Figure 15. Soot precursors in grams per gram of fuel as a function of temperature after ignition, for three values of $\tau$ separated by factors of $10\left(10^{-5} \mathrm{~s}, 10^{-4} \mathrm{~s}\right.$ and $\left.10^{-3} \mathrm{~s}\right)$. 